\title{
PENGEMBANGAN SEBUAH METODE INTERAKTIF UNTUK PENYELESAIAN MASALAH PROGRAM LINIER BILANGAN BULAT KELAS STOKASTIK MULTIOBJEKTIF
}

\author{
Oleh: Suparni ${ }^{1}$
}

\begin{abstract}
Decision problems of stochastic or probabilistic optimization arise when certain coefficient of an optimization model are not fixed or known but are instead, to some extent, stochastic (or random or probabilistic) quantities. This paper focused on multi objective stochastic optimization. We propose a method for solving a multi objective chance constraints integer programming problem based on interactive approach. We assume that there is randomness in the right-hand sides of the constraints only and that the random variables are normally distributed.
\end{abstract}

\begin{abstract}
Abstrak
Masalah keputusan optimasi stokastik atau probabilistik muncul ketika koefisien tertentu dari model optimisasi tidak tetap atau diketahui tetapi sebaliknya, sampai batas tertentu, jumlah stokastik (atau acak atau probabilistik). Karya ilmiah ini berfokus pada optimasi stokastik multitujuan. Kami mengusulkan sebuah metode untuk memecahkan masalah kendala integer kesempatan pemrograman multi-tujuan berdasarkan pendekatan interaktif. Kami berasumsi bahwa ada keacakan di sisi kanan kendala saja dan bahwa variabel acak terdistribusi normal.
\end{abstract}

Kata Kunci: Pemrograman linear integer multiobjek; teknik chance-constrained; pendekatan interaktif

\section{PENDAHULUAN}

Masalah yang berhubungan dengan pengambilan keputusan khususnya pada masalah optimasi stokastik atau probabilistik timbul ketika koefisien model optimasi tidak ditentukan bahkan tidak diketahui. Pada Tahun-tahun terakhir ini metode optimasi stokastik multiobjektif semakin berkembang pesat dan sangat diperlukan dalam dunia ilmu pengetahuan dan tekhnologi. Hal ini didasarkan kepada pembuatan keputusan yang menyangkut masalah praktek yang timbul dalam 
berbagai bidang seperti bidang ekonomi, industri, perawatan kesehatan, transportasi, pertanian, militer dan tekhnologi, merujuk kepada web site pemrogram stokastik (2002)[10]. beberapa literatur terdapat beberapa tulisan yang membahas tentang penyelesaian masalah optimasi program linier bilangan bulat kelas stokastik multiobjektif. Diantaranya beberapa keputusan ditunjukkan untuk membuat masalah stabil [3, 4, 8, 17].

Akhir-akhir ini banyak penulis yang membahas tentang masalah pemrograman stokastik integer multiobjektif telah dipublikasikan, sebagai contoh, $[9,10,14]$. In [9], algoritma penyelesaian masalah pemrograman bilangan bulat dengan variabel random pada fungsi objektifnya dan parameter random pada pembatas juga dibahas. Keunggulan dari algoritma yang ditawarkan adalah adanya peluang pada fungsi pembatasnya [13], juga dengan metode cutting-plane dari Gomory [16]. Saad pada [10] menyampaikan teori dan metodologi yang telah dikembangkan untuk digunakan pada masalah yang lebih komplek pada masalah optimasi dibawah ketidakpastian. Sebagai tambahan, kelebihan dan kekurangan model ini juga dibahas. Aplikasi dan seni dalam perhitungan juga dipaparkan. Ketepatan solusi dari program linier bilangan bulat kelas stokastik multiobjektif juga diselidiki pada [13], dimana masalah meliputi parameter random hanya pada ruas kanan pembatas dan parameter random tersebut berdistribusi normal.

Tulisan ini diawali dengan bagian 2 yaitu dengan merumuskan model dari masalah program linier bilangan bulat dengan kendala berpeluang/chanceconstrained multiobjective integer linear programming problem (CHMOILP) dan menunjukkan konsep penyelesaian. Pada bagian 3, pembahasan parameter pada masalah yang diteliti, dimana beberapa dugaan kestabilan dasar dikemukakan pada rumusan model. Dugaan ini adalah himpunan dari parameter yang mungkin; himpunan pemecahan, dan himpunan kesetabilan jenis pertama/the stability set of the first kind (SSK1). Selain itu, dideskripsikan sebuah algoritma untuk menentukan (SSK1) untuk (CHMOILP). Pada bagian 4, disajikan sebuah contoh sebagai ilustrasi dari hasil.

\section{PEMBAHASAN}

1. Pernyataan Masalah dan Konsep Penyelesaiannya

Masalah program linier bilangan bulat dengan kendala berpeluang dan parameter acak di ruas kanan pembatas dapat dinyatakan sebagaia berikut: 


$$
\begin{aligned}
& \text { (CHMOILP): } \max _{\operatorname{dimana}} F(x), \quad \text { dengan } x x, \\
& X=x \quad R^{n} \mid P\left\{g_{i}(x){ }_{j=1}^{n} a_{i j} x_{j} b_{i}\right\} \quad \alpha_{i}, i=1,2, \ldots, m, x_{j}
\end{aligned}
$$

Dalam hal ini $x$ adalah verktor keputusan bilangan bulat dan $F(x)$ adalah vektor k-linear nilai real fungsi tujuan untuk dimaksimumkan. Selanjutnya, $P$ menyatakan probabilitas dan i $\alpha$ adalah nilai probabilitas yang ditetapkan. Artinya bahwa pembatas linier mungkin dat menggangu beberapa waktu dan paling tidak 100(1- i) \% dari waktu. Untuk penyederhanaan, kita asumsikan bahwa paariabel acak $b_{i}$, ( $i=1,2, \ldots \mathrm{m}$ ) berdistribusi normal dengan diketahui nilai rata-rata $\mathrm{E}\{\mathrm{bi}\}$ dan vaariansi $\operatorname{Var}\{\mathrm{bi}\}$ dan keduanya saling bebas.

Defenisi 1.

Sebuah bilangan $\mathrm{x}^{*} \mathrm{X}$ dikatakan penyelesaian yang efisien untuk masalah $\left(\right.$ CHMOILP) jika tidak ada $x X$ yang lain sedemikian hingga $F(x) \geq F\left(x^{*}\right)$ dan $F(x) \neq$ $\mathrm{F}\left(\mathrm{x}^{*}\right)$ dengan

$$
\mathrm{P}\left\{\mathrm{g}_{\mathrm{i}}\left(\mathrm{x}{ }_{\mathrm{j}=1}^{\mathrm{n}}\right) \mathrm{a}_{\mathrm{ij}} \mathrm{x}{ }_{j} \mathrm{~b}_{\mathrm{i}}\right\} \quad \alpha_{\mathrm{i}}, \mathrm{i}=1,2, \ldots, \mathrm{m}
$$

Ide dasar perlakuan dalam masalah (CHMOILP) adalah mengkonversi sifat masalah yang berbentuk probabilitas menjadi bentuk deterministikis. Di sini ide pemanfaatan versi deterministik akan diilustrasikan dengan menggunakan tekhnik yang sangat penting dari program kendala berpeluang [11]. Dalam hal ini, himpunan pembatas $X$ dari masalah (CHMOILP) dapat ditulis ulang dalam bentuk deterministik sebagai berikut:

$$
X^{\prime}=\begin{array}{lll|l}
x^{n} & R^{n}
\end{array}
$$

Dimana $\mathrm{K}_{i}$ adalah nilai standar normal sedemikian hingga $\left(\mathrm{K}_{i}\right)=1-{ }_{i}$; dan

$$
\sqrt{\mathrm{x}_{\mathrm{j}} \quad \mathrm{E}\left\{\mathrm{b}_{\mathrm{i}}\right\}}+\mathrm{K}_{i} \quad \operatorname{Var}\left\{\mathrm{b}_{\mathrm{i}}\right\}, \mathrm{i}=1,2, \ldots, \mathrm{m}, \mathrm{x}_{\mathrm{j}} \quad \text { Oand integer, } \mathrm{j}=1,2, \ldots, \mathrm{n}
$$

Dimana $\mathrm{K}_{i}$ adalah nilai standar normal sedemikian hingga $\left(\mathrm{K}_{i}\right)=1-{ }_{i}$; dan

$\Phi(a)$ menyatakan "fungsi distribusi kumulative" dari distribusi standar normal yang di evaluasi pada a. Dengan demikian, masalah (CHMOILP) dapat dipahami sebagai versi deterministik dari masalah program linier bilangan bulat multiobjektif sebagai berikut:

(MOILP): $\max \left[\mathrm{f}_{1}(\mathrm{x}), \mathrm{f}_{2}(\mathrm{x}), \ldots, \mathrm{f}_{\mathrm{k}}(\mathrm{x})\right]$, dengan $\mathrm{x} \mathrm{X}^{\prime}$.

Sekarang dapat perhatikan, dari sifat masalah (MOILP) di atas, bahwa tekhnik penskalaran yang tepat untuk dilakukan pada masalah seperti itu adalah 
menggunakan metode pemabatas $\varepsilon$ [2]. Dalam hal ini, kita anggap masalah program linier bilangan bulat berikut dengan fungsi tujuan tunggal sebagai

berikut: $\operatorname{Ps}(\varepsilon)$ : $\max \mathrm{f}_{\mathrm{s}}(\mathrm{x})$, dengan

$$
X()=\left\{\begin{array}{lllll}
x & R^{n} \mid f_{r}(x), r & K-\{S\}, x & X^{\prime}
\end{array}\right\}
$$

Dimana $s \mathrm{~K}=\{1,2, \ldots, \mathrm{k}\}$ yang dapat berubah-ubah.

Dapat dibuat pernyataan dalam hal ini bahwa sulusi efisien $x^{*}$ pada masalah (CHMOILP) dapat diperoleh dengan menyelesaikan masalah skalar $\mathrm{P}_{\mathrm{s}}(\varepsilon)$ dan ini dapat dilakukan jika jika level minimum yang diperkenankan $(\varepsilon 1$, $\varepsilon 2, \ldots, \varepsilon s-1, \varepsilon s+1, \ldots, \varepsilon k)$ untuk (k-1) tujuan $\left(f_{1}, f_{2}, \ldots, f_{s-1}, f_{s+1}, \ldots, f_{k}\right)$ telah ditentukan pada daerah feasible dari penyelesaian $\mathrm{X}(\varepsilon)$.

Telah jelas dari [2] bahwa variasi yang sistematis dari $\varepsilon^{i}$ akan menghasikan sebuah himpunan penyelesaian yang efisien. Di sisi lain, hasil masalah skalar $\mathrm{P}_{\mathrm{s}}(\varepsilon)$ dapat diselesaikan dengan mudah pada parameter tertentu $\varepsilon=\varepsilon^{\star}$ menggunakan metode branch-and bound [14]. Jika $x^{*} X\left(\varepsilon^{*}\right)$ adalah sebuah penyelesaian optimal yang unik dari masalah $\mathrm{P}_{\mathrm{s}}\left(\varepsilon^{*}\right)$, makax menjadi sebuah penyelesaian efisien masalah (CHMOILP) dengan level probabilitas ${ }_{i}^{*},(i=1,2, \ldots \mathrm{m})$.

\section{Pernyataan Masalah}

Masalah pemrograman bilangan bulat (IGP) dapat dinyatakan secara $\underset{\substack{\text { monnutean } \\ \text { matis }}}{\text { matis }}$

\section{bilangan bulat}

Dimana 1 dan 2 adalah vektor yang menyatakan besar violation dari pembatas. dan adalah variabel yang ditunjukkan dengan seberapa banyak tujuan yang diberikan adalah violated.

Catatan bahwa pembatas yang diberikan baik maupun adalah tertentu untuk menjadi nol pada penyelesaian optimal.

Seperti yang telah kita ketahui bahwa tujuan pemrograman adalah masalah struktur dari pemrograman tujuan ganda. Oleh karena itu dalam menurunkan metode untuk menyelesaikan pemrograman bilangan bulat kita berangkat dengan menyelesaikan menyelesaikan pemrograman bilanan bulat tujuan ganda. (MOIP). Anggap masalah MOIP (Multi Objectives Integer Programming) adalah: 
$\max [()$, $\epsilon]$

dengan

Dimana $=\{1,2, \ldots$,$\} , adalah sebuah matrik koefisien dengan ukuran \times \underset{\epsilon}{\in}$ dari batasan/kendala; adalah -vector dari ruas kanan, $\epsilon ;(), \epsilon$, adalah fungsi linier dari variabel keputusan, adalah -vector dari variabel keputusan, $\epsilon$ dan adalah batas atas dari .

\section{Analisis Hirarki Proses}

AHP dikemukakan oleh Saaty $[11,12]$ dua puluh tahun yang lalu dan

diperluas penggunaan tekhniknya pada pengambilan keputusan dengan multiattribute. Nilai eigen untuk setiap elemen lalu digunakan untuk menaksir kontribusi elemen tersebut kepada komponen secara keseluruhan. Sebagai anjuran, hirarki dari matrik dapat digunakan komponennya adalah komponennya sendiri dari urutan komponen diatasnya. Sebagai contoh yang lebih khusus adalah sebagai dasar seorang suplayor dalam menentukan banyak kriteria seperti harga dan kualitas. Kita akan menentukan kontribusi relatif dari harga dan kualitas kepada keputusan secara menyeluruh.

Angaplah terdapat $n$ anggota, maka kita memerlukan ( $(-1)) / 2$ pasangan keputusan untuk melengkapi matrik, dimana setiap keputusan menggambarkan tanggapan dari rasio kontribusi relatif dari elemen dan kepada komponen secara menyeluruh yang ditaksir sedemikian $=(/)$, merujuk ke kendala berikut; $>0,=1$ dan $=(1 /)$. Saaty menunjukkan bahwa tekhnik hanya akan efektif digunakan dimana elemen homogen, oleh karena itu rasio haarus berada pada rentang $1 / 9$ sampai 9 .

Untuk membuat perbandingan lebih mudah, beberapa peneliti melampirkan nama yang berkaitan dengan arti kata misalnya "sama dengan" dimana rasionya adalah 1, "sedikit lebih penting" yang mana itu adalah 2 dan seterusnya. misalnya, jika kita mempertimbangkan kualitas menjadi "sedikit lebih penting" dari pada harga, satu akan ditempatkan nilai dua pada sel yang tepat pada matrik. Dalam hal ini matrik kompletnya sebagai berikut:

\begin{tabular}{|c|c|c|}
\hline & Quality & Cost \\
\hline Quality & 1 & 2 \\
\hline Cost & 0.5 & 1 \\
\hline
\end{tabular}


Setiap bagian mempunyai skala prioritas, yang diperoleh dari skala rasio, untuk mengukur kontribusi setiap elemen kepada komponen tersebut. Masalah yang dapat terjadi, terutama dikarenakan keputusan yang subjektif, adalah penempatan nilai yang tidak konsisten. ketetapan sebagai tolak ukur dari simpangan dari nilai eigen matrik dari orde matrik.

Ketetapan indeks, , dihitung sengan cara berikut:

dimana max adalah nilai eigen pokok maksimum dari matrik keputusan. Semakin mendekati nol semakin konsisten keputusan. Cl dapat dibandingkan dengan indeks konsistensi dari matrik acak (). Perbandingan ( / ) diketahui sebagai konsitensi perbandingan ( ). Saaty menganjurkan harus kurang dari 0.1 , walaupun satu one akan menjadi perhatian tentang nilai yang tidak begitu berarti.

defenisi. Reference direction didefenisikan sebagai perbedaan antara reference point yang diberikan dengan DM dan solusi masalah yang terahir.

Misalkan menunjukkan nilai yang berubah-ubah dari fungsi objektif (1) dan- menunjukkan level aspirasi. Selanjutnya misalkan,

$$
=\left[\epsilon^{\top} \Gamma^{\top}\right]=\left[\epsilon^{-} \Gamma^{\top}<\right]=\left[\epsilon^{-} \Gamma^{-}=\right]
$$

Dimana $=u$ u. Untuk mendapatkan solusi selanjutnya dari (1), kita selesaikan masalah tujuan tunggal pengganti berikut:

dengan

dimana $Q_{\text {adalah parameter non negatif dan }}^{-}, \in$ is adalah nilai fungsi objektif yang diperoleh pada penyelesaian terahir. $\max \in 1()$

Fungsi objektif (2), memaksimalkan standarisasi terkecil perbedaan antara solusi sekarang () dan solusi terahir untuk semua fungsi objektif $\in$. Selanjutkan akan membawakita sejauh mungkin dari penyelesaian sekarang. Ketika kita menyelesaikan (2). nilai fungsi objektif yang masuk kepada himpunan $H$ meningkat masuk ke himpunan $L$ dapat berkurang. dengan demikian 
fungsi (1) mengandung hanya dalam ${ }^{-}>$ untuk paling sedikit satu' $\epsilon$. Inז', $\epsilon$, tidak harus mengandung solusi juga berakibat bahwa reference point sebelumnya dari (1).

Berdasarkan nilai dari-dan di atas , $\in$, himpunan , dan adalah terbentuk yang didefenisikan sebagai masalah tujuan tunggal (2). Jika himpuana $H$ dan $L$ bukan himpunan kosong, maka solusi optimal (2) diperoleh untuk nilai yang bervariasi dan merupakan solusi efisien yang lemah dari (1). Perlu untuk dicatat bahwa penyelesaian terhir dari (1) adalah solusi yang mungkin dari (2); ini penting ketika penyelesaian (2) dengan algoritma yang tepat. selanjutnya, solusi yang mungkın dari (2) mungkin salah untuk penyelesaian efisien dari (1) yang membolehkan kita untuk menggunakan algoritma perkiraan untuk menyelesaikan (2).

Karena fungsi objektif (2) tidak linier, maka tidak ada algoritma yang standar untuk digunakan menyelesaikan masalah pemrograman linier bilangan bulat. Akan tetapi, masalah dapat dimulai dengan masalah program linier bilangan bulat campuran yang ekuivalen berikut.

max

dengan:

dimana adalah sebuah scalar. Jika (2) tidak ada solusi, (5) juga tidak ada solusi. Ini menunjukkan bahwa kedua masalah memiliki pembatas yang sama. Jika (2) tidak ada solusi, (5) memiliki solusi dan nilai optimal dari fungsi objektif mereka adalah sama. Karena masalah (2) dan (5) adalah ekuivalen, solusi optimal (5) adalah solusi efisien yang lemah dari (1).

Solusi dari (2) (atau yang setara (B)) adalah sebuah solusi efisien yang lemah untuk (1). Akan tetapi, jika itu diperlukan untuk mendapatkan sebuah solusi yang efisien, maka kit a dapat menyelesaikan masalah tujuan tunggal pengganti berikut ini:

$\max ()=\max \{\min$

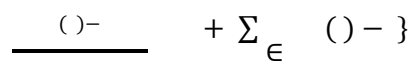

dengan: 
dimana $G$ adalah angka positif yang sangat kecil yang berubah-ubah. masalah (11) dapt di reduksi menjadi bentuk program linier bilangan bulat campuran yang ekuivalen berikut ini:

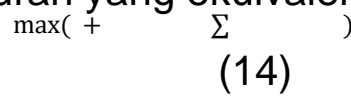

dengan

3. Algoritma yang diusulkan

Algoritma yang diusulkan terdiri dari tiga langkah sebagai berikut.

- Langkah 1. Tentukan sebuah solusi efisien yang lemah awal.

- Langkah 2. Tunjukkan solusi pada DM. jika DM sesuai dengan solusi, berhenti: sebaliknya, minta DM untuk menetapkan sebuah reference point ${ }^{\top}$ yang baru, gunakan AHP dan gpergi ke langkah 3. (solusi terahir), selesaikan (5)

(atau 11)) dan tentukan solusi efisien lemah lanjutan yang baru (atau efisien) (); lanjut ke langkah 2

$\in \operatorname{dan}^{-}=1, \epsilon$. Jika nilai untuk beberpa , $\in$ dapat menjadi negatif, maka masalah (5) atau (14) dapat diselesaikan dengan mengganti $y$ by $1-2$ dimana $1,2 \geq 0$. Karena (2) dan (14) merupakan masalah pemrograman linier bilngan bulatcampuran, keduanya dapat diselesaikan dengan beberapa algoritma

standar yang tepat. algoritma branch-and-bound adalah yang paling tepat untuk tujuan ini. Karena kita mulai dengan solusi feasibel awal untuk masalah, waktu solusi putaran berikut (langkah 3) dapat benar-benar diturunkan. Kita awali dengan 
menyelesaikan masalah untuk $=0$ dan dapat dilanjutkan dengan penyelesaian prasedur parametrik untuk beberapa nilai $\alpha_{\text {yang baru. }}$

Masalah (5) dan (14) adalah NP-hard. Algoritma yang tepat dapat mengambil waktu sedapat mungkin untuk menyelesaikan masalah dengan dimensi yang lebih besar. Oleh karena itu, itu diperlukan untuk digunakan untuk memperkirakan algoritma untuk menyelesaikan masalah pada langkah 3 . Berdasarkan theorema solusi feasible diperoleh dengan memperkirakan algoritma lie close to atau efisien lemah (atau efisien); juga digunakan untuk merumuskan masalah (5) atau (14) untuk putaranberikutnya. Pernyataan sebelumnya adalah benar jugang tepat digunakan untuk menyelesaikan (5) dan (14).

Ada dua cara untuk menghindari masalah ini. Cara pertama adalah mengharuskan DM membuatlevel aspirasi sedemikian hingga

untuk paling sedikit satu . walaupun, ini mengambil sebuah kendala tambahan pada DM. Cara kedua untuk menghindari masalah adalah dengan menyelesaikan (22) (atau (26)) terlebih (5) (atau (14)).

yaitu ,

dengan

atau

dimana

dan 
Sayang sekali, solusi efisien lemah (atau efisien) yang terakhir dapat tidak fiasibel untuk (22) (atau (26)); dan tidak ada kepastian yang dapat dikatakan tentang penyelesaian feasible untuk masalah ini atau apakah mereka akansedikit berbohong tentang hasil yang efisien untuk (1).

\section{DAFTAR PUSTAKA}

Balinski, M., "An Algorithm for Finding All Vertices of Convex Polyhedral Sets", SIAM Journal, Vol. 9, No. 1, 1961.

Chankong, V. and Haimes, Y. Y., "Multiobjective Decision-Making: Theory and Methodology" (North Holland Series in System Science and Engineering), 1983.

El-Banna, A. Z. and Youness, E. A., "On Some Basic Notions of Stochastic Multiobjective Problems with Random Parameters in the Constraint"s, Microelectronics. Reliability, Vol. 33, No. 13, 1993, 1981-1986.

Guddat. J., Vasquez, F., Tammer, K. and Wendler, K., "Multiobjective and Stochastic Optimization Based on Parametric Optimization", AkademieVerlage, Berlin, 1985.

Osama, Ez-Eldin., "On Stochastic Multiobjective Integer Linear Programming Problems", M.SC. Thesis, Helwan University, Cairo, Egypt, 2000.

Osman, M. S. A., "Qualitative Analysis of Basic Notions in Parametric Convex Programming I" (Parameters in the Constraints), Applied. Math. CSSR Akad. Ved. Prague, 22, 1977.

Osman, M. S. A., "Qualitative Analysis of Basic Notions in Parametric Convex Programming II" (Parameters in the Objective Function), Applied. Math. CSSR Akad. Ved. Prague, 22, 1977.

Osman, M. S. A. and Saad, O. M., "On the Solution of Chance-Constrained Multiobjective Linear Programming Problems with A Parametric Study," Proceedings of the First International Conference on Operations Research and its Applications, Higher Technological Institute, Ramadan Tenth. City, Egypt, 1994.

Saad, O. M. and Kittani, H. F., "Multiobjective integer linear programming problems under randomness", IAPQR TRANSACTIONS, Vol.28, No.2, 2003, 101-108. 
Saad, O. M., "Optimization under uncertainty: A State-of-the-Art, Paper accepted for publication in Applied Mathematics and Computation", 2006.

Saaty T. L., The Analytic Hierarchy Process. McGraw-Hill. New York, 1980

Saaty T. L., Hightlights and critical pints in the theory and applications of the analytic hierarchy process. EJOR, 74(3) (1994).

Seppälä, Y., "On Accurate Linear Approximations for Chance-Constrained Programming", Journal of Operational. Research. Society, Vol. 39, No. 7, 1998.

Sharif,W.H. and Saad, O.M., "On stability in multiobjective integer linear programming: A stochastic approach", American Journal of Applied Sciences, Vol. 2, No. 12, 2005.

Stochastic Programming Web Site, (2002), http:// Stoprog.org, Current as of July 2002.

Taha, H. A., "Integer Programming: Theory, Applications and Computations", Academic Press, New York, 1975.

Vogel, S., "On Stability in Multiobjective Programming-A Stochastic Approach", Mathematical Programming, 60, 1992. 